\title{
Teores de proteína bruta para bovinos alimentados com feno de capim- tifton 85: parâmetros ruminais, eficiência de síntese microbiana e degradabilidade in situ ${ }^{1}$
}

\author{
Edilane Aparecida da Silva ${ }^{2}$, Telma Teresinha Berchielli ${ }^{3}$, Ricardo Andrade Reis ${ }^{3}$, Alexandre \\ Vaz Pires ${ }^{4}$, Kátia Junko Sato ${ }^{5}$, José Mauro Valente Paes ${ }^{6}$, André Dias Lopes ${ }^{7}$ \\ ${ }^{1}$ Parte da tese de Doutorado da primeira autora realizada pelo Programa de Pós-Graduação em Zootecnia da UNESP de Jaboticabal. Projeto \\ financiado pela FAPESP. \\ 2 EPAMIG, Bolsista de Produtividade da FAPEMIG. R. Afonso Rato 1301, CEP: 38001-970, Uberaba - MG. \\ ${ }^{3}$ FCAVIUNESP - Via de Acesso Prof. Paulo Castellane, $s / n$, Jaboticabal-SP. Pesquisador do CNPq. \\ ${ }^{4}$ ESALQ/USP - Piracicaba/SP. Pesquisador do CNPq. \\ ${ }^{5}$ Curso de Zootecnia na FCAV/UNESP - Jaboticabal-SP. \\ ${ }^{6}$ EPAMIG, Bolsista de Produtividade da FAPEMIG. \\ 7 Mestrando em Zootecnia da UNESP de Jaboticabal.
}

RESUMO - Avaliou-se o efeito da deficiência de PB na dieta sobre a eficiência de síntese microbiana e a degradabilidade in situ da MS e FDN em novilhos mestiços. Os tratamentos consistiram de dietas compostas de feno de tifton 85 (FN) suplementadas com uréia (FNUR), farelo de soja (FNFS) e farelo de glúten de milho- 60 (FNGL). Foram utilizados oito novilhos canulados no rúmen e no duodeno, distribuídos em dois quadrados latinos 4 x 4 . O pH e a concentração de nitrogênio nãoamoniacal $\left(\mathrm{N}_{-} \mathrm{NH}_{3}\right)$ foram mensurados no fluido ruminal antes e 2, 4, 6 e 8 horas após o fornecimento da ração, utilizando-se a fibra em detergente ácido indigestível (FDAi) como indicador do fluxo duodenal. A eficiência microbiana foi determinada por meio das bases purinas. Em todas as dietas, o $\mathrm{pH}$ e a concentração de $\mathrm{N}-\mathrm{NH}_{3}$ foram adequados para o crescimento dos microrganismos ruminais. Não houve efeito da deficiência de PB na dieta sobre a ingestão de MS, a eficiência de síntese microbiana e a cinética de degradação da MS e FDN do feno de tifton 85. O teor de PB das dietas não alterou o crescimento microbiano, a eficiência de síntese microbiana e a cinética de degradação ruminal.

Palavras-chave: concentração de amônia, farelo de glúten de milho-60, farelo de soja, pH, purina, uréia

\section{Effects of crude protein levels on microbial efficiency and in situ degradability in steers fed Tifton 85 bermudagrass hay supplemented with different protein sources}

\begin{abstract}
Eight crossbred steers fitted with ruminal and duodenal cannulas were randomly assigned to two replicated 4 x 4 Latin squares to evaluate the effects of crude protein (CP) levels on microbial protein synthesis efficiency and in situ degradability of nutrients. Animals received a control diet containing Tifton 85 bermudagrass hay or the control diet supplemented with urea, soybean meal or corn gluten meal-60. Ruminal $\mathrm{pH}$ and concentration of ruminal ammonia $\left(\mathrm{NH}_{3}-\mathrm{N}\right)$ were determined in the ruminal fluid at 0 (pre-feeding), 2, 4, 6 and 8 hours after feeding. Indigestible acid detergent fiber was used as the internal marker for measuring duodenal flow of nutrients while total purines were used as the direct microbial marker to measure microbial protein synthesis and microbial efficiency. Ruminal $\mathrm{pH}$ and $\mathrm{NH}_{3}-\mathrm{N}$ were within expected ranges indicating a stable ruminal environment. There were no effects of different dietary CP levels on intakes of DM and N as well as on microbial efficiency and degradability kinetics of DM and NDF. It can be concluded that different CP levels had no effect on microbial protein synthesis and efficiency and kinetics of ruminal degradability.
\end{abstract}

Key Words: corn gluten meal 60, $\mathrm{pH}$, ruminal ammonia, purines, soybean meal, urea

\section{Introdução}

A diversidade e os arranjos químicos encontrados na parede celular dos tecidos vegetais sugerem que a extração dos nutrientes pelo sistema digestivo dos ruminantes seja diferenciada. A degradabilidade ruminal da MS, ou das diferentes frações que a compõem, é um dos parâmetros pelos quais a expressão desta diversidade pode ser mais facilmente comprovada.

A degradação protéica ruminal consiste em um processo complexo, com múltiplas etapas, que envolve solubilização, hidrólise extracelular, transporte, desaminação 
e formação de produtos finais, como amônia, ácidos graxos voláteis, $\mathrm{CO}_{2}$ e metano (Owens \& Zinn, 1988). Quando o conteúdo de proteína excede os requisitos dos microrganismos, ocorre sua fermentação a amônia, a qual é absorvida pela parede do rúmen, sendo convertida em uréia no fígado e excretada na urina, caracterizando a ineficiência do aproveitamento (Russell et al., 1992).

Os sistemas de balanceamento de dietas atuais visam ajustar a disponibilidade de energia do substrato para os microrganismos com suas demandas de $\mathrm{N}$ (amônia e/ou aminoácidos). De acordo com Souza et al. (2002), a digestão da fibra é afetada pelo teor de proteína das dietas, principalmente daquelas à base de forragem de baixa qualidade, visto que a deficiência de proteína limitaria a atividade ruminal afetando a ingestão e a digestibilidade dos nutrientes. Isso ocorre porque as exigências de proteína dos ruminantes são atendidas pelos aminoácidos provenientes da proteína microbiana e da proteína dietética não degradada no rúmen. A exigência mínima de $\mathrm{N}$ para a digestão máxima não é constante, mas muda com a disponibilidade de energia e com a qualidade do volumoso utilizado, portanto, persistem ainda dúvidas quanto à necessidade de $\mathrm{N}$ para degradação da fibra e para máximo crescimento microbiano.

A suplementação protéica de dietas à base de volumosos pode ter efeito aditivo sobre a digestão da fibra, pois permite otimizar o ambiente ruminal de modo a favorecer o crescimento dos microrganismos. De acordo com Galyean \& Owens (1991), a suplementação protéica de forragem com baixo teor de PB e alto teor de fibra muitas vezes melhora a digestão e, conseqüentemente, a taxa de passagem e a ingestão voluntária. Todavia, estes resultados não são freqüentemente registrados na literatura.

Em estudo com fontes de proteína não degradável no rúmen (PNDR) e proteína degradável no rúmen (PDR), farelo de glúten de milho-60 e farelo soja, Souza et al. (2002) encontraram maior degradabilidade efetiva da fibra do capim-coastcross (Cynodon dactylon) na dieta com farelo de glúten de milho-60, observando-se que esta dieta não promoveu alteração na atividade microbiana, no pH ruminal ou na taxa de diluição do rúmen.

Outro parâmetro que pode ser utilizado para verificar se a dieta fornecida é adequada às características fisiológicas do ruminante é a concentração de nitrogênio amoniacal $\left(\mathrm{N}-\mathrm{NH}_{3}\right)$ no rúmen. A concentração mínima necessária para manutenção da taxa máxima de crescimento microbiano varia conforme a fermentação da dieta. $\mathrm{O}$ aumento da concentração ruminal de amônia com a elevação do teor de PB da dieta foi verificado por Roffler \& Satter (1974).
A degradabilidade das proteínas pode afetar o crescimento microbiano, de modo que aquelas de maior degradabilidade ruminal promovem maior crescimento microbiano (Russell et al., 1992; Christensen et al., 1993). Conforme Owens \& Goetsch (1988), a eficiência de síntese microbiana pode ser reduzida quando não há proteína verdadeira na dieta. A síntese de proteína microbiana no rúmen é insuficiente para satisfazer às necessidades em proteína no caso de animais de alta produção. Assim, a inclusão de proteínas que escapam à degradação ruminal é necessária para maximizar a produção (Christensen et al., 1993).

Este estudo foi realizado com o objetivo de avaliar o efeito do fornecimento de dietas com nível níveis insuficientes de PDR e/ou PB, formuladas com feno de capim-tifton 85 moído como volumoso, suplementado com uréia, farelo de soja ou farelo de glúten de milho-60, sobre a eficiência de síntese microbiana e a degradabilidade in situ da MS e FDN.

\section{Material e Métodos}

O experimento foi conduzido no Setor de Avaliação de Alimentos e de Digestibilidade, do Departamento de Zootecnia da Faculdade de Ciências Agrárias e Veterinárias da UNESP, Campus de Jaboticabal - SP, no período de janeiro a junho de 2001.

Foram utilizados oito novilhos mestiços (Holandês $\mathrm{x}$ Zebu), canulados no rúmen e no duodeno, com peso médio de $240 \mathrm{~kg}$, alojados em baias com cochos individuais e bebedouros comuns a duas baias. Antes do experimento, os animais foram tratados contra endo e ectoparasitas, sendo pesados no início e ao final de cada período experimental.

Os tratamentos foram constituídos de feno de tifton 85 (FN), suplementado com diferentes fontes de $\mathrm{N}$ : uréia (FNUR), farelo de soja (FNFS) e farelo de glúten de milho-60 (FNGL). As dietas suplementadas eram isoprotéicas e foram formuladas com base no teor de PB dos alimentos, considerando os requisitos de proteína para mantença, de acordo com o AFRC (1993), com base no N endógeno basal, que inclui as perdas urinárias endógenas, parte do $\mathrm{N}$ metabólico fecal e as perdas por descamação de tecidos e pêlos, admitindo-se eficiência de utilização igual a 1 . No tratamento referente à uréia, adicionou-se sulfato de amônio na proporção de 9:1 e, para suprir o déficit de energia, utilizou-se $\mathrm{o}$ amido de milho. A água foi fornecida à vontade e todos os animais receberam aproximadamente $50 \mathrm{~g}$ de sal mineral, fornecido juntamente com as rações. O capim-tifton 85 foi colhido aos 90 dias de rebrota e conservado na forma de feno. O feno foi moído em fragmentos de aproximadamente $10 \mathrm{~cm}$ de comprimento e fornecido uma vez ao dia, às $7 \mathrm{~h}$, em 
quantidade calculada para ocorrer aproximadamente $10 \%$ de sobras por animal.

A composição química dos ingredientes e a composição percentual e química das dietas, de acordo com os tratamentos, são indicadas na Tabela 1 .

O experimento foi dividido em quatro períodos experimentais de 27 dias (14 de adaptação dos animais às dietas e 13 para as coletas de conteúdo ruminal, digesta duodenal e incubação dos sacos de náilon). No 15o dia de cada período experimental, foi coletado o líquido ruminal para isolamento das bactérias uma hora após a alimentação. As digestas sólida e líquida de rúmen foram coletadas (cerca de 3,0 L), homogeneizadas manualmente com 1,0 L de solução salina $1 \mathrm{~N}$ e misturadas em tecido duplo de algodão, compondo amostras líquidas de aproximadamente 2,0 L, que foram armazenadas em frascos de plástico com tampa rosqueada e congeladas $\mathrm{a}-10^{\circ} \mathrm{C}$. $\mathrm{O}$ isolamento das bactérias das amostras de digesta ruminal foi feito por procedimentos de centrifugações diferenciais, conforme metodologia descrita por Cecava et al. (1990). Após o isolamento, as amostras foram liofilizadas e analisadas quanto aos teores de MS, cinzas e $\mathrm{N}$ total, segundo procedimentos citados por Silva \& Queiroz (2002). O teor de nitrogênio nãoamoniacal (NNA) no duodeno foi obtido pela diferença entre a concentração de $\mathrm{N}$-total e a de $\mathrm{N}-\mathrm{NH}_{3}$ da digesta duodenal.

Do 20 o ao 25 o dia de cada período experimental, realizou-se o ensaio de degradabilidade. Sacos de náilon $100 \%$ poliamida $(14 \times 7 \mathrm{~cm})$, resistentes a alta temperatura, não resinados, com poros de 40 e $50 \mathrm{~m}$ e contendo

Tabela 1 - Composição química, valores de EB (kcal/kg MS), estimativa da proteína degradável (D) dos ingredientes, composição percentual e química das dietas (\%MS) e ingestão diária de proteína degradável (IPD) das dietas

Table 1 - Chemical composition, GE (kcal/kg DM), and estimated degradable protein (D) of ingredients, chemical and ingredient composition (\%DM) of diets, and daily ingestion of dietary degradable protein (IDP)

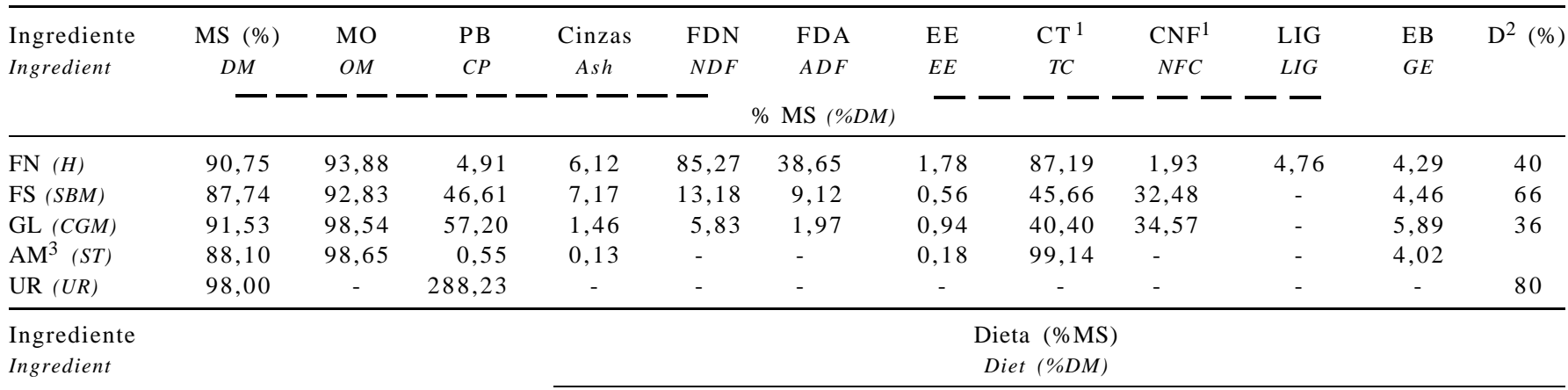

\begin{tabular}{lrrr} 
& FN $(H)$ & FNUR $(H U R)$ & FNFS $(H S B M)$ \\
\hline FN $(H)$ & 99,20 & 94,02 & 94,03 \\
Uréia (Urea) & - & 0,87 & - \\
FS (SBM) & - & - & - \\
GL (CGM) & - & - & - \\
Amido (Starch) & 0,80 & 4,31 & - \\
Mistura mineral (Mineral mixture) & 0,80 & - \\
\hline
\end{tabular}

\section{Nutriente}

Nutrient

\begin{tabular}{|c|c|c|c|c|}
\hline $\operatorname{MS}(D M)$ & 90,81 & 90,74 & 90,64 & 90,84 \\
\hline MO (OM) & 93,10 & 92,5 & 93,09 & 93,09 \\
\hline $\mathrm{PB}(C P)$ & 4,87 & 7,12 & 7,00 & 7,01 \\
\hline $\operatorname{PDR}(R D P)$ & 39,88 & 38,68 & 41,18 & 39,92 \\
\hline PNDR (RUP) & 59,29 & 56,23 & 58,04 & 59,28 \\
\hline Cinzas (Ash) & 6,07 & 5,76 & 6,13 & 6,11 \\
\hline $\mathrm{EB}(\mathrm{kcal} / \mathrm{kg} \mathrm{MS})(G E \mathrm{kcal} / \mathrm{kg} D M)$ & 4,26 & 4,22 & 4,27 & 4,27 \\
\hline $\mathrm{FDN}(N D F)$ & 84,56 & 80,17 & 80,85 & 81,62 \\
\hline FDA $(A D F)$ & 38,33 & 36,34 & 36,81 & 37,13 \\
\hline EE & 1,76 & 1,68 & 1,70 & 1,71 \\
\hline $\mathrm{CT}^{1}(T C)$ & 86,47 & 86,27 & 84,38 & 84,82 \\
\hline $\mathrm{CNF}^{1}(N F C)$ & 1,91 & 1,82 & 3,30 & 3,01 \\
\hline IPD (g/dia) $(I D P$, g/day $)$ & 91,31 & 179,23 & 161,22 & 128,22 \\
\hline
\end{tabular}

FN = feno de capim-tifton $85 ; F S=$ farelo de soja; $G L=$ glúten de milho-60; $A M=$ amido; UR = uréia; FNUR = FN+uréia; FNFS = FN+farelo de soja; $\mathrm{FNGL}=\mathrm{FN}+$ glúten de milho-60.

${ }^{1} \mathrm{CT}=100-\left(\% \mathrm{~PB}+\% \mathrm{\% E}+\%\right.$ cinzas) e CNF = CT - FDN (Sniffen et al., 1992); ${ }^{2}$ NRC (2001); ${ }^{3}$ Rostagno et al. (1992).

$H=$ Tifton-85 bermudagrass hay; $S B M=$ soybean meal; $C G M=60$ corn gluten meal; $S T=$ starch; $U R=$ urea.

${ }^{1} T C=100-(\% C P+\% E E+\%$ ash) and NFC $=$ TC-NDF (Sniffen et al., 1992). 
aproximadamente $5 \mathrm{~g}$ de feno moído foram selados em seladora a quente, submersos em água à temperatura ambiente por 1 hora e depois foram colocados, simultaneamente, no rúmen de oito bovinos, sendo mantidos presos à tampa de cada cânula ruminal por uma corrente de metal de $50 \mathrm{~cm}$ de comprimento. Após os tempos de 3, 6, 12, 24, 48, 72, 96 e 120 horas de incubação, os sacos foram retirados considerando-se a ordem do menor para o maior tempo. Depois de retirados do rúmen, os sacos foram imersos imediatamente em água fria e lavados até que a água ficasse transparente e, posteriormente, foram secos em estufa de ventilação forçada (a $55^{\circ} \mathrm{C}$ por 48 horas) e pesados. Para obtenção da fração solúvel, dois sacos de náilon de cada material foram incubados em água por uma hora a $39^{\circ} \mathrm{C}$, sendo lavados manualmente e secos em estufa a $55^{\circ} \mathrm{C}$ por 48 horas. A diferença de peso (antes e após o tratamento) foi considerada a fração solúvel a do modelo proposto por Ørskov \& McDonald (1979).

A degradabilidade potencial (DP) da MS foi calculada segundo o modelo proposto por Ørskov \& McDonald (1979):

$$
\mathrm{DP}=\mathrm{a}+\mathrm{b}\left(1-\mathrm{e}^{-\mathrm{c} . \mathrm{t}}\right), \text { para } \mathrm{t}>\mathrm{L}
$$

em que: $a=$ fração imediatamente solúvel, $b=$ fração insolúvel mas potencialmente degradável, $\mathrm{c}=$ taxa constante de degradação da fração $b, t=$ tempo de incubação e $L=$ tempo de colonização; e a DP da FDN foi calculada segundo o modelo $\mathrm{Y}=\mathrm{b}+\mathrm{i}$, para $0<\mathrm{t}<\mathrm{L}$ e $\mathrm{Y}=\mathrm{b}^{*} \mathrm{e}^{(-\mathrm{c} *(\mathrm{t}-\mathrm{L})}+\mathrm{i}$, para $\mathrm{t}>$ L proposto por Mertens \& Loften (1980), em que: Y = resíduo de incubação, $\mathrm{b}=$ fração insolúvel mas potencialmente degradável, $\mathrm{c}=$ taxa constante de degradação da fração $b, t=$ tempo de incubação, $i=$ fração indigestível e $\mathrm{L}=$ tempo de colonização. As degradabilidades efetivas (DE) foram calculadas por meio da equação proposta por Ørskov \& McDonald (1979), considerando-se taxa de passagem de $2 \%$, sendo $\mathrm{DE}=\mathrm{a}+\mathrm{b} \cdot \mathrm{c} /(\mathrm{c}+\mathrm{k})$, em que: $\mathrm{a}=$ fração solúvel em água; $b$ = fração insolúvel em água, mas potencialmente degradável; $\mathrm{c}=$ taxa constante de degradação da fração b; e k = taxa de passagem da fração sólida do conteúdo ruminal.

Do 210 ao 24 으 dia de cada período experimental, foram coletadas amostras de digesta duodenal, via cânula, para determinação do fluxo duodenal. As coletas foram feitas durante os quatro dias, três vezes ao dia, a intervalos de 8 horas, com intervalo de 6 horas entre dias, a fim de que, no final de quatro dias, fossem obtidas 12 amostras de digesta duodenal por animal. O esquema foi o seguinte: dia 1 coletas às 8,16 e 24 h; dia 2 - coletas às 6,14 e $22 \mathrm{~h}$; dia 3 - coletas às 4, 12 e $20 \mathrm{~h}$; e dia 4 - coletas às 2,10 e $18 \mathrm{~h}$. As amostras foram armazenadas a $-5^{\circ} \mathrm{C}$ e, posteriormente, foram pré-secas em estufa ventilada a $55^{\circ} \mathrm{C}$ (por 72 a 96 horas) e trituradas em moinho com peneira de $2 \mathrm{~mm}$. Em cada período de coleta, elaborou-se uma amostra composta por animal, com base no peso seco de cada subamostra. As amostras compostas foram devidamente acondicionadas em recipientes e, posteriormente, submetidas a análises laboratoriais para determinação das purinas e posterior estimativa do fluxo de $\mathrm{N}$ microbiano, por meio da relação $\mathrm{N}$ purinas: $\mathrm{N}$ bacteriano total pelo procedimento descrito por Zinn \& Owens (1986), com modificações propostas por Ushida et al. (1985).

No 26- dia de cada período experimental, foram coletadas amostras de líquido ruminal antes e 2, 4, 6, e 8 horas após o fornecimento da dieta visando à determinação do $\mathrm{pH}$ e das concentrações de $\mathrm{N}-\mathrm{NH}_{3}$. Depois de homogeneizadas as amostras, determinou-se o $\mathrm{pH}$ utilizando-se peagâmetro digital e adicionou-se a cada amostra $1 \mathrm{~mL}$ de solução de $\mathrm{H}_{2} \mathrm{SO}_{4}$ 1:1 para cessar a fermentação. As amostras foram armazenadas a $-5^{\circ} \mathrm{C}$ para posterior determinação das concentrações de $\mathrm{N}-\mathrm{NH}_{3}$ por destilação com hidróxido de potássio $2 \mathrm{~N}$.

A taxa de passagem de fluidos foi determinada no 270 dia utilizando-se Co-EDTA como indicador (Úden et al., 1980), fornecido em dose única de 50 g por animal, diluída em 500 mL de água destilada e infundida, através da cânula, diretamente no rúmen de cada animal. As amostragens de líquido ruminal foram realizadas a cada 2 horas até completar 12 horas. Para determinação da concentração de cobalto no indicador, foi realizada digestão nítrico-perclórica; as amostras de líquido ruminal foram descongeladas e centrifugadas a $500 \mathrm{~g}$ por 15 minutos e a leitura do sobrenadante foi realizada em espectrofotômetro de absorção atômica. O volume do rúmen, a taxa de passagem da fase líquida, a taxa de reciclagem e o fluxo total de líquidos foram estimados utilizando-se os parâmetros da equação de regressão linear do logaritmo natural das concentrações de cobalto $(\mathrm{mg} / 100 \mathrm{~mL})$ nas amostras de líquido ruminal, sendo as concentrações do indicador as variáveis dependentes e os horários, as independentes.

Os teores de MS, N total, FDN, FDA, cinzas, lignina e EE das amostras de digesta duodenal e dos componentes da ração foram estimados conforme metodologias descritas por Silva \& Queiroz (2002) e os de EB foram determinados em bomba calorimétrica adiabática PARR Instruments.

Na determinação dos fluxos diários de MS no duodeno, utilizou-se como indicador interno a FDAi, obtida pelo método in vitro, após 144 horas de incubação (Berchielli et al., 2000b). Para os cálculos de fluxo de MS duodenal, foi utilizada a equação descrita por Berchielli et al. (1998): 
Fluxo de MS duodenal $=\frac{\text { MS fecal } \times \text { FDA indigestível na MS fecal }}{\% \text { FDA indigestível na MS duodenal }}$

$\mathrm{Na}$ análise estatística dos resultados, utilizaram-se dois quadrados latinos $4 \times 4$, com quatro animais, quatro tratamentos e quatro períodos experimentais. A análise de variância e a comparação de médias pelo teste Tukey, a 5\% de significância, foram obtidas pelo programa SAS (SAS, 1999).

\section{Resultados e Discussão}

Os dados das estimativas das concentrações de $\mathrm{N}-\mathrm{NH}_{3}$ e do $\mathrm{pH}$, de acordo com os diferentes tempos de coleta ruminal, encontram-se na Tabela 2.

A dieta com maior quantidade de proteína degradável no rúmen (FNUR) apresentou maior $(\mathrm{P}<0,05)$ concentração de $\mathrm{N}-\mathrm{NH}_{3}$ em relação àquela sem suplementação protéica, não se observando diferença entre as demais (Tabela 2). Ocorreu interação significativa tratamentos $x$ tempos de coleta das amostras, verificando-se efeito quadrático dos tempos de coleta sobre a concentração de $\mathrm{N}-\mathrm{NH}_{3}$ na dieta FNUR. A partir da derivação da regressão, estimou-se a concentração máxima de $\mathrm{N}-\mathrm{NH}_{3}$ no líquido ruminal dos animais que receberam a dieta FNUR, de $18,85 \mathrm{mg} / 100 \mathrm{~mL}$, obtida no tempo de 4,73 horas após a alimentação, evidenciando maior atividade microbiana no rúmen neste período.
Valores similares foram obtidos por Cavalcante et al. (2006), que, utilizando novilhos mestiços alimentados com dietas contento quatro níveis de PB $(10,5 ; 12,0 ; 13,5$ e $15,0 \%$ ), estimaram valor máximo de $17,43 \mathrm{mg} / \mathrm{dL}$ de $\mathrm{N}-\mathrm{NH}_{3}$ 3,62 horas após a alimentação. Efeito quadrático na concentração de N-NH $\mathrm{N}_{3}$ também foi encontrado por Roffler \& Satter (1974) a partir dos dados de 211 vacas em 35 experimentos nos quais a concentração de $\mathrm{PB}$ da dieta variou de 8 a 24,7\%.

Os valores de $\mathrm{N}^{-\mathrm{NH}_{3}}$ no líquido ruminal situaram-se sempre acima de $5 \mathrm{mg} / 100 \mathrm{~mL}$ (Satter \& Slyter, 1974), apesar da deficiência em PDR, o que pode ser explicado pela contribuição endógena de $\mathrm{N}$ no rúmen, pois quanto menor o teor de $\mathrm{PB}$ na dieta maior a reciclagem de $\mathrm{N}$ para o rúmen via amônia proveniente do fígado na forma de uréia (Owens \&Zinn, 1988).

A deficiência de PDR e/ou PB ou as diferentes fontes de $\mathrm{N}$ na dieta não ocasionaram diferenças no $\mathrm{pH}$ do líquido ruminal (Tabela 2). Nas quatro dietas estudadas, houve interação significativa tratamentos $\times$ tempos de coleta, portanto, procedeu-se à análise de regressão em função do tempo de coleta. As equações de regressão que melhor explicaram a variação no $\mathrm{pH}$ ruminal em função do tempo são descritas na Tabela 2.

$\mathrm{O} \mathrm{pH}$ do fluido ruminal, como observado também por Bürger et al. (2000), diminuiu de forma linear com o aumento dos tempos de coleta. $\mathrm{O}$ pH ruminal dos animais recebendo a dieta FNUR foi influenciado quadraticamente pelos tempos de coleta; a partir da derivação da equação, estimou-se que

Tabela 2 - Médias e equações de regressão ajustadas da concentração de $\mathrm{N}^{-\mathrm{NH}_{3}}$ e do pH do líquido ruminal, de acordo com os tempos de coleta das diferentes dietas

Table 2 - Mean and adjusted regression equations for the ruminal concentration of $\mathrm{NH}_{3}-\mathrm{N}$ and ruminal $\mathrm{pH}$ on different diets

\begin{tabular}{|c|c|c|c|c|c|c|c|c|}
\hline & & $\mathrm{N}-\mathrm{N}$ & $(\mathrm{mg} / 10$ & $\mathrm{mL})$ & & \multirow{3}{*}{$\begin{array}{l}\text { Média } \\
\text { Mean }\end{array}$} & \multirow{3}{*}{$\begin{array}{l}\text { Equação de regressão } \\
\text { Regression equation }\end{array}$} & \multirow{3}{*}{$\mathrm{R}^{2}$} \\
\hline & \multicolumn{5}{|c|}{$\begin{array}{l}\text { Tempo } \\
\text { Time }\end{array}$} & & & \\
\hline & 0 & 2 & 4 & 6 & 8 & & & \\
\hline $\mathrm{FN}(H)$ & 6,47 & 8,02 & 8,28 & 7,80 & 7,68 & $7,65 b$ & $\hat{\mathrm{y}}=\bar{y}=7,65$ & - \\
\hline FNUR (HUR) & 10,27 & 14,00 & 18,39 & 20,19 & 13,38 & $15,25 \mathrm{a}$ & $\hat{\mathrm{y}}=9,384441+3,99979 \mathrm{X}-0,422359 \mathrm{~T}^{2}$ & 0,86 \\
\hline FNFS $(H S B M)$ & 11,22 & 14,29 & 11,76 & 10,60 & 8,99 & $11,37 \mathrm{ab}$ & $\hat{y}=\bar{y}=11,37$ & - \\
\hline $\begin{array}{l}\text { FNGL }(H C G M) \\
\mathrm{pH}\end{array}$ & 10,20 & 11,51 & 11,55 & 9,58 & 8,34 & $10,23 \mathrm{ab}$ & $\hat{\mathrm{y}}=\bar{y}=10,26$ & - \\
\hline $\mathrm{FN}(H)$ & 6,79 & 6,70 & 6,60 & 6,59 & 6,55 & 6,65 & $\hat{y}=6,76675-0,03025 \mathrm{~T}$ & 0,91 \\
\hline FNUR (HUR) & 6,88 & 6,99 & 6,91 & 6,84 & 6,70 & 6,86 & $\hat{\mathrm{y}}=6,89411+0,045805 \mathrm{~T}-0,00886163 \mathrm{~T}^{2}$ & 0,96 \\
\hline FNFS $(H S B M)$ & 6,91 & 6,85 & 6,73 & 6,74 & 6,61 & 6,77 & $\hat{\mathrm{y}}=6,912-0,036 \mathrm{~T}$ & 0,94 \\
\hline FNGL $(H C G M)$ & 6,81 & 6,84 & 6,79 & 6,67 & 6,63 & 6,75 & $\hat{y}=6,84875-0,025875 \mathrm{~T}$ & 0,83 \\
\hline
\end{tabular}

$\mathrm{FN}=$ feno de tifton 85, FNUR = FN+uréia, FNFS = FN+farelo soja, FNGL = FN+glúten de milho-60.

$H=$ Tifton-85 bermudagrass hay; $H U R=H+$ urea; $H S B M=H+$ soybean meal; $H C G=H+60$ corn gluten meal.

$\mathrm{R}^{2}=$ coeficiente de determinação (Coefficient of determination).

Médias seguidas de letras diferentes, nas colunas, diferem pelo teste Tukey $(P<0,05)$.

Means followed by different capital letter within column and small letters within rows are different $(P<0.05)$ by Tukey test. 
o valor máximo de $\mathrm{pH}$ ocorreu 2,58 horas após a alimentação, sendo obtido valor de 6,95 na dieta composta de feno+uréia. De acordo com Franco et al. (2002), em ambiente ruminal normal, o pH varia de 5,5 a 7,0, valores similares aos encontrados nesse trabalho. Pode-se supor, então, que o ambiente ruminal apresentava condições ideais para a atividade das bactérias celulolíticas, que necessitam de $\mathrm{pH}$ de 6,0 a 6,7 (Owens \& Goetsch, 1988; Russell et al., 1992) em dietas constituídas de volumosos.

Esses resultados comprovaram, no entanto, tendência inversa ao padrão encontrado na literatura, com valores máximos de $\mathrm{N}-\mathrm{NH}_{3}$ e mínimos de $\mathrm{pH}$ após a ingestão de alimento. Todavia, como a dieta foi composta quase que exclusivamente de feno, esse efeito pode ter contribuído para os resultados obtidos, pois, quando a dieta é constituída somente de volumoso, geralmente provoca maior mastigação e ruminação e, conseqüentemente, aumento na produção de saliva e elevação do pH. Outra explicação para estes resultados é que a dieta contendo uréia, por sua solubilidade e mais rápida hidrólise para formação de amônia, também tende a acarretar $\mathrm{pH}$ ruminal mais elevado.

Dados da literatura também apontam comportamento atípico de pH. Detmann et al. (2005), utilizando novilhos alimentados com dietas com dietas contendo 12 a $24 \%$ de $\mathrm{PB}$, observaram $\mathrm{pH}$ mais elevado a 1,9 hora após o fornecimento dos suplementos $(6,54)$. Cavalcante et al. (2006) verificaram pH máximo de 6,54 no tempo de 4,17 horas após a alimentação.

$\mathrm{Na}$ Tabela 3 constam os resultados relativos à composição química das bactérias ruminais, aos consumos de MS e $\mathrm{N}$, aos fluxos de $\mathrm{MO}, \mathrm{N}$ total ( $\mathrm{N}$-total), $\mathrm{N}$ microbiano (N-mic) e N não-amoniacal (NNA).

A deficiência de PB e/ou PDR na dieta não causou diferença significativa na composição química das bactérias ruminais. Quanto às diferentes fontes de $\mathrm{N}$, não houve diferenças $(P>0,05)$ na composição química das bactérias nas diferentes dietas, o que está de acordo com os resultados descritos por Branco et al. (2001), que não encontraram efeito das fontes nitrogenadas de diferentes degradabilidades sobre a taxa de degradação ruminal da PB e a composição das bactérias. Os autores obtiveram valores médios na composição das bactérias ruminais de $91,95 \%$ de MS, $75,57 \%$ de MO e $5,17 \%$ de N-total, ao trabalharem com uréia, farinha de penas e farelo de glúten de milho-60, respectivamente.

A ausência de efeito das dietas sobre a composição das bactérias pode ser explicada pelos valores de $\mathrm{pH}$ ruminal semelhantes entre as dietas (Tabela 2). Ressalta-se que valores de $\mathrm{pH}$ diferentes poderiam causar variações entre as populações das diversas espécies de microrganismos, o que poderia resultar em diferença na composição bacteriana decorrente das dietas.

Os teores médios de $\mathrm{MO}$ e $\mathrm{N}$-total observados (Tabela 3) estão abaixo dos valores descritos pelo Cornell Net Carbohydrate and Protein System (CNCPS), que recomenda valores de 95,6 e 10\%, respectivamente (Russell et al., 1992). Contudo, os altos teores de cinzas, freqüentemente observados em análises de microbiota ruminal, podem ser causados por contaminação com solução salina utilizada no processo de isolamento (Mendes et al., 2006).

Entretanto, os valores médios de MO, N-total, RNA, $\mathrm{N}$-RNA encontram-se de acordo com os dados de literatura compilados por Clark et al. (1992), que descrevem variações na composição microbiana de 60,8 a $92,2 \%$ de MO, 4,83 a $10,58 \%$ de N-total, 2,4 a $13,2 \%$ de RNA e 0,5 a $1,89 \%$ de N-RNA. Do mesmo modo, Valadares Filho et al. (1990a) encontraram valores de 81,86 a 89,95 de MS, 61,17 a $79,42 \%$ de MO e 5,48 a $6,5 \%$ de $\mathrm{N}$-total em novilhos $7 / 8$ Holandês-Zebu alimentados com dietas formuladas com $55 \%$ de silagem de milho e $45 \%$ de concentrado.

Os teores médios de MS, N-total e N-RNA foram próximos aos reportados na literatura brasileira (Bürger et al., 2000). Mendes et al. (2006) avaliaram o efeito da substituição parcial do milho pela casca de soja e pelo farelo de gérmen de milho em dietas à base de silagem de milho em novilhos mestiços e encontraram menores teores de MO e RNA (57 e 4,05\% respectivamente) e valores semelhantes para N: RNA e N-RNA:N total $(0,60$ e 0,12 respectivamente).

As diferentes fontes de $\mathrm{N}$ não afetaram $(\mathrm{P}>0,05)$ a quantidade de $\mathrm{N}$ ingerido e os fluxos de $\mathrm{MO}$ e $\mathrm{N}$ microbiano para o duodeno. Como as rações eram isoprotéicas, não foi observada diferença nos níveis de ingestão de $\mathrm{N}$ pelos animais entre as dietas suplementadas. A suplementação da dieta com farelo de glúten de milho- 60 aumentou o fluxo de N-total e N não amoniacal em 33 e $37 \%$, respectivamente, em relação à dieta contendo uréia. O maior fluxo de $\mathrm{N}$-total $(\mathrm{P}<0,05)$ obtido com a dieta FNGL pode ser explicado pelo fato de que a farinha de glúten de milho-60 é uma fonte de $\mathrm{N}$ de baixa degradabilidade no rúmen, o que aumenta o fluxo de $\mathrm{N}$ para o duodeno.

Em consonância com os resultados obtidos nesse trabalho, Branco et al. (2001), avaliando o efeito de três fontes nitrogenadas, observaram valores médios de fluxo duodenal de $\mathrm{N}$ não amoniacal de 47,58 g/dia e de $\mathrm{N}$-total de 42,02 $\mathrm{g} /$ dia quando forneceram uréia e farinha de penas e também não encontraram efeito das fontes nitrogenadas sobre os parâmetros avaliados.

Os valores médios de MO aparentemente digerida no rúmen (MOADR), carboidratos totais disponíveis no rúmen 
Tabela 3 - Composição química das bactérias do rúmen, ingestão de MS e $\mathrm{N}$ e fluxos de $\mathrm{MO}, \mathrm{N}$ microbiano (N-mic) e $\mathrm{N}$ não-amoniacal (NNA) para o duodeno, de acordo com as diferentes dietas

Table 3 - Chemical composition of ruminal bacteria, intakes of DM and N, and duodenal flows of microbial OM, microbial $N$ (mic- $N$ ), and non-ammonia $N$ (NAN) on different diets

\begin{tabular}{|c|c|c|c|c|c|c|}
\hline & \multicolumn{4}{|c|}{$\begin{array}{c}\text { Composição das bactérias ruminais } \\
\text { Ruminal bacteria composition }\end{array}$} & \multirow{3}{*}{$\begin{array}{l}\text { Média } \\
\text { Mean }\end{array}$} & \multirow{3}{*}{$\mathrm{CV}(\%)$} \\
\hline & \multicolumn{4}{|c|}{$\begin{array}{c}\text { Dieta } \\
\text { Diet }\end{array}$} & & \\
\hline & $\mathrm{FN}(H)$ & FNUR (HUR) & FNFS $(H S B M)$ & FNGL $(H C G M)$ & & \\
\hline MS $(\%)(D M)$ & 94,04 & 94,17 & 94,20 & 94,04 & 94,11 & 0,82 \\
\hline $\mathrm{MO}^{1}(O M)$ & 71,12 & 69,57 & 69,42 & 70,16 & 70,07 & 6,66 \\
\hline N-total ${ }^{1} \quad($ Total-N) & 5,35 & 5,14 & 5,55 & 5,52 & 5,39 & 7,90 \\
\hline $\mathrm{RNA}^{1}$ & 6,60 & 6,29 & 7,22 & 7,09 & 6,80 & 18,22 \\
\hline $\mathrm{N}-\mathrm{RNA}^{1}(R N A-N)$ & 0,62 & 0,60 & 0,69 & 0,65 & 0,64 & 17,91 \\
\hline $\mathrm{N}-\mathrm{RNA}^{2}: \mathrm{N}$ total $(R N A-N: T N)$ & 0,14 & 0,14 & 0,14 & 0,14 & 0,14 & 0,72 \\
\hline \multicolumn{7}{|c|}{$\begin{array}{l}\text { Consumo } \\
\text { Intake }\end{array}$} \\
\hline MS ingerida $(\mathrm{kg} / \mathrm{dia})$ (Ingested $D M, \mathrm{~kg} /$ day) & 4,69 & 4,70 & 4,81 & 4,65 & 4,71 & 16,11 \\
\hline $\begin{array}{l}\mathrm{N} \text { ingerido ( } \mathrm{g} / \mathrm{dia} \text { ) (Ingested } \mathrm{N}, \mathrm{g} / \text { day) } \\
\text { Fluxo para duodeno (Duodenal flow) }\end{array}$ & $36,79 b$ & $58,90 \mathrm{a}$ & $57,34 \mathrm{a}$ & $58,06 \mathrm{a}$ & 52,77 & 12,29 \\
\hline MO (g/dia) $(O M, g / d a y)$ & 2287,00 & 2119,90 & 2218,40 & 2186,40 & 2202,93 & 16,98 \\
\hline $\mathrm{N}$ total (g/dia) (Total $N$, g/day) & $40,64 \mathrm{ab}$ & $35,48 \mathrm{~b}$ & $40,67 \mathrm{ab}$ & $47,32 \mathrm{a}$ & 41,03 & 27,48 \\
\hline $\mathrm{N}$-mic (g/dia) (mic- $N$, g/day) & 32,80 & 31,08 & 28,30 & 29,79 & 30,49 & 27,15 \\
\hline NNA (g/dia) $(N A N$, g/day $)$ & $36,62 a b$ & $31,56 \mathrm{~b}$ & $36,43 a b$ & $43,25 \mathrm{a}$ & 36,96 & 20,11 \\
\hline $\mathrm{pH}$ no duodeno (Duodenal $\mathrm{pH}$ ) & 2,49 & 2,53 & 2,51 & 2,42 & 2,49 & 12,78 \\
\hline
\end{tabular}

FN = feno de tifton 85; FNUR = FN+uréia; FNFS = FN+farelo de soja; FNGL = FN+glúten de milho-60.

Médias seguidas de letras diferentes na mesma linha diferem $(P<0,05)$ pelo teste Tukey.

$1 \%$ na MS $(\% D M) ;{ }^{2} \% \mathrm{~N}$ no RNA $=14,80 \%$.

$H=$ Tifton- 85 bermudagrass hay; $H U R=H+$ urea; $H S B M=H+$ soybean meal; $H C G M=H+60$ corn gluten meal.

Means, in the same row, followed by different letters, differ $(P<0.05)$ by Tukey test.

Tabela 4 - Valores médios de MO aparentemente digerida no rúmen (MOADR), carboidratos totais disponíveis digeridos no rúmen (CHODR), energia digestível no rúmen (EDR), e eficiência de síntese de proteína microbiana estimada por meio das purinas nas diferentes dietas

Table 4 - Mean values of OM apparently digested in the rumen (OMDR), total carbohydrates digested in the rumen (CHODR), energy digested in the rumen $(D E R)$ and microbial protein synthesis efficiency on the different diets

\begin{tabular}{|c|c|c|c|c|c|c|}
\hline & \multicolumn{4}{|c|}{$\begin{array}{c}\text { Dieta } \\
\text { Diet }\end{array}$} & \multirow[t]{2}{*}{$\begin{array}{l}\text { Média } \\
\text { Mean }\end{array}$} & \multirow[t]{2}{*}{$\mathrm{CV}(\%)$} \\
\hline & $\mathrm{FN}(H)$ & FNUR $(H U R)$ & FNFS (HSBM) & FNGL $(H C G M)$ & & \\
\hline $\begin{array}{l}\text { MOADR (kg/dia) } \\
\text { OMDR (kg/day) }\end{array}$ & 2,04 & 2,16 & 2,13 & 2,19 & 2,13 & 2,04 \\
\hline CHODR (kg/dia) & 2,04 & 2,17 & 1,96 & 2,04 & 2,05 & 2,04 \\
\hline $\begin{array}{l}\text { CHODR (kg/day) } \\
\text { EDR (MJ/dia) } \\
\text { DER (MJ/day) }\end{array}$ & 36,29 & 38,35 & 38,70 & 38,64 & 37,99 & 18,47 \\
\hline \multicolumn{7}{|c|}{$\begin{array}{l}\text { Eficiência de síntese microbiana } \\
\text { Microbial protein synthesis efficiency }\end{array}$} \\
\hline $\begin{array}{l}\text { g N-mic/kg MOADR } \\
\text { g mic-N/kg OMDR }\end{array}$ & 15,23 & 13,66 & 13,13 & 13,90 & 13,98 & 18,20 \\
\hline $\begin{array}{l}\text { g N-mic/kg CHODR } \\
\text { g mic-N/kg CHODR }\end{array}$ & 15,21 & 13,49 & 14,30 & 14,79 & 14,45 & 18,71 \\
\hline $\begin{array}{l}\text { g N-mic/MJ EDR } \\
\text { g mic-N/kg/MJ DER }\end{array}$ & 0,86 & 0,77 & 0,73 & 0,78 & 0,78 & 17,99 \\
\hline $\begin{array}{l}\text { g PB-mic/100 g NDT } \\
\text { g mic-CP/100 g NDT }\end{array}$ & 9,05 & 7,14 & 10,72 & 8,01 & 8,73 & 18,60 \\
\hline
\end{tabular}

FN = feno de tifton 85; FNUR = FN+uréia; FNFS = FN+farelo de soja; FNGL = FN+glúten de milho-60.

$H=$ Tifton-85 bermudagrass hay; $H U R=H+$ urea; $H S B M=H+$ soybean meal; $H C G M=H+60$ corn gluten meal. 
(CHODR), energia digestível no rúmen (EDR), eficiência de síntese microbiana em g N-mic/kg MOADR, g N-mic/kg CHODR, g N-mic/MJ EDR e g PB-mic/100 g NDT podem ser observados na Tabela 4.

As quantidades MOADR, CHODR e EDR não foram influenciadas pela deficiência de PDR e/ou PB na dieta. Os valores médios de MOADR e CHODR foram superiores aos encontrados por Bürger et al. (2000), de 1,42 e 1,52 kg/dia, respectivamente.

A deficiência de PDR e/ou PB não influenciou a eficiência de síntese microbiana em $\mathrm{g} \mathrm{N}$-mic/kg de MOADR e CHODR, g N-mic/MJ de EDR e g PB-mic/100 g NDT. A dieta sem suplementação tendeu a apresentar maiores valores de eficiência de síntese de proteína quando expressa $\mathrm{g} \mathrm{N}$-mic/kg MOADR $(\mathrm{P}<0,16)$ e em $\mathrm{g} \mathrm{N}$-mic/MJ EDR $(\mathrm{P}<0,14)$, provavelmente pelo fato de a energia ter sido disponibilizada em pequenas quantidades para os microrganismos, aumentando a eficiência de aproveitamento de $\mathrm{N}$ no rúmen, ou ainda em virtude da maior contribuição do $\mathrm{N}$ reciclado, que pode também aumentar a síntese de proteína. Estes resultados também estão de acordo com os menores níveis de digestibilidade ruminal da PB (Silva et al., 2007) e N-NH 3 no líquido ruminal (Tabela 2), indicando utilização mais eficiente de $\mathrm{N}$ no rúmen dos animais alimentados com esta dieta.

Quando o N não-protéico (no caso a uréia) é ministrado a um animal com quantidade inadequada de energia disponível no rúmen, o pico de amônia é alto (Tabela 2), mas a produção de proteína microbiana é baixa, o que aumenta as perdas de $\mathrm{N}$ e diminui o fluxo de compostos nitrogenados para o duodeno, o que pode ser comprovado pela baixa eficiência de síntese de proteína microbiana dos animais alimentados com uréia (Tabela 4). Deve-se considerar, no entanto, que os animais desse tratamento tiveram ingestão de PDR mais alta (179,23 g/dia, Tabela 1$)$ em relação àqueles dos outros tratamentos.

Os valores estimados de eficiência de síntese microbiana expressos em MOADR foram inferiores às médias relatadas por Bürger et al. (2000), Fregadolli et al. (2001), mas foram similares aos obtidos por Berchielli et al. (1995) e Detmann et al. (2005). Quanto à CHODR, a eficiência de síntese microbiana apresentou valores estimados inferiores às médias relatadas por Berchielli et al. (1995) e Bürger et al. (2000) e foram inferiores também ao valor médio de $32 \mathrm{~g}$ $\mathrm{N}$-mic/kg MOADR descrito pelo ARC (1984).

Para a eficiência de síntese de proteína microbiana em $\mathrm{g} \mathrm{N}$-mic/MJ EDR, os valores foram similares aos obtidos por Berchielli et al. (1995). Pode-se afirmar que há grande similaridade entre MOADR e energia digerida no rúmen, pois neste trabalho os maiores valores de EDR obtidos na dieta
FN e FNGL, apesar de não-significativos, corresponderam aos maiores valores de digestibilidade da MO nas mesmas dietas (63,61 e 69,17\%), respectivamente (Silva et al., 2007).

Os valores médios encontrados para eficiência de síntese microbiana em $\mathrm{g}$ PB-mic/100 $\mathrm{g}$ NDT foram inferiores ao recomendado pelo NRC (2001), de $13 \mathrm{~g}$ PB-mic/100 g NDT. Foram próximos, no entanto, aos obtidos por Cavalcante et al. (2006), ao utilizarem níveis de $12 \%$ PB na dieta para bovinos de corte alimentados com $65 \%$ de feno de tifton 85 e 35\% de concentrado (10,6 g PB-mic/100 g NDT).

Os baixos valores de eficiência de síntese de proteína microbiana podem ser atribuídos ao inadequado suprimento de PDR e/ou PB e de energia provenientes da dieta, visto que o volumoso consistiu de feno de baixa qualidade $(4,91 \%$ PB e $85,27 \%$ FDN). Além disso, segundo Clark et al. (1992) e NRC (2001), as disponibilidades ruminais de energia e $\mathrm{N}$ são os fatores que mais limitam o crescimento microbiano. De acordo com esses autores, para potencializar a fermentação e a síntese de proteína microbiana no rúmen, é necessária a sincronização da disponibilidade da energia fermentável e do $\mathrm{N}$ degradável no rúmen.

Como não houve manutenção de níveis adequados de $\mathrm{N}$ no rúmen, presume-se que os metabólitos energéticos tiveram baixo aproveitamento, acarretando menor eficiência de síntese de proteína microbiana. Do mesmo modo, como havia deficiência de proteína e as fermentações de carboidratos foram extensas, não houve acoplamento de $\mathrm{N}$ e energia, o que minimizou a eficiência de síntese de proteína microbiana. As menores quantidades de amônia produzidas no rúmen (Tabela 2) propiciadas pelos menores consumos de $\mathrm{N}$ (Tabela 3 ) também podem ter contribuído para o limitado crescimento microbiano. Quando há interação degradação de proteína $\times$ degradação de carboidratos, ocorre elevado desenvolvimento de microrganismos, que se dividem mais rapidamente e são mais eficientes na utilização de ATP. Portanto, presume-se também que essa taxa de renovação dos microrganismos não ocorreu de forma tão eficaz, minimizando, juntamente com outros fatores, a eficiência de síntese de proteína microbiana.

Quando se utilizam dietas com elevados teores de volumosos, pode ocorrer deficiência de energia disponível e aumento da reciclagem de compostos nitrogenados pelos microrganismos do rúmen, diminuindo a passagem de proteína microbiana para o intestino delgado (Clark et al., 1992), o que também pode ter contribuído para os menores valores de eficiência de síntese de proteína microbiana neste experimento.

Segundo Detmann et al. (2005), quando são utilizadas forragens de baixa qualidade, é necessária a inclusão de carboidratos prontamente degradáveis no rúmen, que irão 
disponibilizar energia mais rapidamente, melhorando a capacitação de $\mathrm{N}^{-\mathrm{NH}_{3}}$ para síntese microbiana e maximizando sua eficiência.

Decréscimos na eficiência de síntese de proteína microbiana com a suplementação protéica têm sido relatados na literatura (Cavalcante et al., 2006; Krysl et al., 1989). Salisbury et al. (2004), avaliando o efeito da suplementação com PDR e PNDR, utilizaram como volumoso feno de gramínea de baixa qualidade e observaram que a eficiência de síntese de proteína microbiana foi maior nos animais do tratamento controle e obtiveram valores de 11,$7 ; 1,4 \mathrm{e}$ $10,2 \mathrm{~g} / \mathrm{kg}$ MOADR nos tratamentos controle, baixa PNDR (24,8 g/dia) e alta PNDR (37,1 g/dia), similares aos obtidos neste estudo. Segundo os autores, outro fator que pode ser considerado quando se obtêm valores mais baixos de eficiência de síntese de proteína microbiana está associado aos problemas com os indicadores utilizados para estimar o fluxo duodenal e o $\mathrm{N}$ microbiano, que também podem contribuir para os valores obtidos neste trabalho.

Fregadolli et al. (2001), trabalhando com fontes de N de diferentes degradabilidades ruminais, não encontraram também efeito das fontes de proteína na eficiência de síntese de compostos nitrogenados. Resultados contraditórios foram relatados por Branco et al. (2001), que obtiveram maior eficiência de síntese na dieta com farelo de glúten de milho-60 (37,16 g/dia) em comparação a dietas com uréia $(22,4 \mathrm{~g} / \mathrm{dia})$ e farinha de penas $(22,85 \mathrm{~g} / \mathrm{dia})$, que não diferiram entre si.

Como descrito na Tabela 5, a deficiência de PDR e/ou PB não ocasionou diferença significativa no volume ruminal, no tempo de retenção e nas taxa de diluição, reciclagem e fluxo ruminal, que não diferiram entre as três fontes de $\mathrm{N}$. Contudo, a dieta sem suplementação protéica resultou em menor taxa de diluição e, conseqüentemente, menor taxa de reciclagem $(\mathrm{P}<0,05)$.
Valadares Filho et al. (1990b), trabalhando com três grupos genéticos (holandês, Nelore e búfalo) alimentados com ração purificada + feno de capim-gordura $(60 \%)$, encontraram valor médio de taxa de diluição líquida de $5,5 \% / \mathrm{h}$, próximo ao encontrado neste trabalho. Bürger et al. (2000), ao fornecerem feno de coastcross como volumoso e farelo de soja e fubá de milho como concentrados, encontraram taxa de diluição de $6,97 \% / \mathrm{h}$ para os animais alimentados com $70 \%$ de volumoso e $30 \%$ de concentrado.

Mendes et al. (2006) observaram valores similares de volume de líquido ruminal de 40,25 (milho), 38,06 (casca de soja) e $34,86 \mathrm{~L}$ (farelo de gérmen de milho). Todavia, encontraram valores médios superiores para taxa de diluição e fluxo de líquido ruminal $(13,39 \% / \mathrm{h}$ e $4,91 \mathrm{~L} / \mathrm{h}$, respectivamente).

O volume ruminal médio observado correspondeu a $14,58 \%$ do peso do animal, próximo aos valores preconizados por Owens \& Goestch (1988) como ideais (15 a $21 \%$ do peso do animal). A quantidade de líquidos que deixou o rúmen por hora foi de 2,36, semelhante às descritas por Valadares Filho et al. (1990b) e Berchielli et al. (1996). Valores médios de taxa de reciclagem superiores foram econtrados por Berchielli et al. (1996) e Bürger et al. (2000), de 2,0 e 2,3 vezes/dia, respectivamente. O tempo médio de retenção, de 17,35 horas, foi similar aos reportados por Bürger et al. (2000), de 15,05 horas.

Embora a variação nas fontes de $\mathrm{N}$ degradável e/ou a deficiência de PB não tenham influenciado as características estudadas, houve aumento de $30 \%$ nas taxas de diluição e reciclagem com a adição das fontes diferenciadas de $\mathrm{N}$, observando-se que, apesar das quantidades mínimas oferecidas de $\mathrm{N}$, os resultados foram bastante similares a outros obtidos com níveis de $\mathrm{N}$ adequados (Berchielli et al., 1996; Bürger et al., 2000).

Os parâmetros de degradação das frações solúvel (a) e solúvel potencialmente degradável (b), a taxa de degrada-

Tabela 5 - Médias de volume, taxa de diluição, tempo de retenção, taxa de reciclagem e taxa de fluxo do fluido ruminal de bovinos, estimadas pelo Co-EDTA nas diferentes dietas

Table 5 - Means of ruminal fluid volume, dilution rate, retention time, turnover rate and flow rate estimated by Co-EDTA on the different diets

\begin{tabular}{|c|c|c|c|c|c|}
\hline \multirow[t]{2}{*}{$\begin{array}{l}\text { Parâmetro } \\
\text { Item }\end{array}$} & \multicolumn{4}{|c|}{$\begin{array}{c}\text { Dieta } \\
\text { Diet }\end{array}$} & \multirow[t]{2}{*}{$\begin{array}{l}\text { Média } \\
\text { Mean }\end{array}$} \\
\hline & $\mathrm{FN}(H)$ & FNUR (HUR) & FNFS $(H S B M)$ & FNGL $(H C G M)$ & \\
\hline Volume de líquido ruminal - (L) (Ruminal fluid volume, $L$ ) & 36,31 & 32,13 & 38,51 & 38,89 & 36,46 \\
\hline Taxa de diluição - $(\% / \mathrm{h})$ (Dilution rate, \%/h) & $5,28 \mathrm{~b}$ & $6,36 \mathrm{a}$ & $8,28 \mathrm{a}$ & $6,00 \mathrm{a}$ & 6,48 \\
\hline Tempo de retenção - $(\mathrm{h})$ (Retention time, $(h)$ & 20,40 & 16,68 & 14,32 & 18,00 & 17,35 \\
\hline Taxa de reciclagem - (vezes/dia) (Turnover rate, times/day) & $1,27 \mathrm{~b}$ & $1,53 \mathrm{a}$ & $1,99 \mathrm{a}$ & $1,44 \mathrm{a}$ & 1,56 \\
\hline Taxa de fluxo - $(\mathrm{L} / \mathrm{h})$ (Flow rate, $L / h)$ & 1,88 & 2,14 & 3,11 & 2,32 & 2,36 \\
\hline
\end{tabular}

FN = feno de capim-tifton 85; FNUR = FN+uréia; FNFS = FN+farelo de soja; FNGL = FN+glúten de milho -60 .

Médias seguidas de letras diferentes na mesma linha diferem $(P<0,05)$ pelo teste Tukey.

$H=$ Tifton-85 bermudagrass hay; $H U R=H+$ urea; $H S B M=H+$ soybean meal; $H C G M=H+60$ corn gluten meal.

Means, in the same row, followed by different letters, differ $(P<0.05)$ by Tukey test. 
Tabela 6 - Fração solúvel (a), fração insolúvel potencialmente degradável (b), degradação potencial (DP) e efetiva (DE), taxa de degradação (c) da MS e FDN, ingestão de MS (IMS) e coeficiente de determinação ( $\left.\mathrm{R}^{2}\right)$ nas diferentes dietas

Table 6 - Soluble fraction (a), insoluble potentially degradable (b), potential degradability (DP) and effective degradability (DE), dry matter (DM) and neutral detergent fiber (NDF) degradation rate (c), DM intake (DMI) and coefficient of determination of the different diets

\begin{tabular}{|c|c|c|c|c|c|c|}
\hline Dieta & $\mathrm{a}$ & $\mathrm{b}$ & DP & $\mathrm{DE}$ & $\mathrm{c}$ & $\mathrm{R}^{2}$ \\
\hline \multirow[t]{2}{*}{ Diet } & & $\%$ & & kp $2 \%$ & $\% / \mathrm{h}$ & \\
\hline & \multicolumn{5}{|c|}{ MS (DM) } & \\
\hline $\mathrm{FN}(H)$ & 14,71 & 43,44 & 58,14 & 44,29 & 4,40 & 0,98 \\
\hline FNUR (HUR) & 15,15 & 42,66 & 57,80 & 38,21 & 2,71 & 0,95 \\
\hline FNFS (HSBM) & 13,66 & 47,82 & 61,48 & 43,89 & 3,97 & 0,98 \\
\hline \multirow[t]{2}{*}{ FNGL $(H C G M)$} & 14,62 & 42,61 & 57,23 & 42,74 & 3,97 & 0,97 \\
\hline & \multicolumn{4}{|c|}{ FDN $(N D F)$} & & \\
\hline $\mathrm{FN}(H)$ & - & 57,10 & 47,10 & 38,83 & 4,44 & 0,98 \\
\hline FNUR (HUR) & - & 55,46 & 50,41 & 36,74 & 4,56 & 0,95 \\
\hline FNFS (HSBM) & - & 57,38 & 45,49 & 40,55 & 5,08 & 0,99 \\
\hline \multirow[t]{2}{*}{ FNGL (HCGM) } & - & 56,63 & 39,59 & 34,70 & 3,58 & 0,97 \\
\hline & $\mathrm{FN}(H)$ & FNUR (HUR) & FNFS $(H S B M)$ & FNGL (HCGM) & Média & $\mathrm{CV}(\%)$ \\
\hline IMS (kg/dia) (DMI, $\mathrm{kg} /$ day $)$ & 4,69 & 4,70 & 4,81 & 4,65 & 4,71 & 16,11 \\
\hline DE PB & 40 & 80 & 66 & 36 & - & - \\
\hline
\end{tabular}

$\mathrm{FN}=$ feno de tifton $85 ; \mathrm{FNUR}=\mathrm{FN}+$ uréia; FNFS = FN+farelo de soja; FNGL = FN+glúten de milho -60 .

$H=$ Tifton-85 bermudagrass hay; $H U R=H+$ urea; $H S B M=H+$ soybean meal; $H C G M=H+60$ corn gluten meal. ${ }^{*}$ NRC (2001).

ção da fração potencialmente degradável (c) e a degradação potencial (DP) não foram afetados pela deficiência de PDR e/ou PB ou pelas diferentes fontes de $\mathrm{N}$ degradável (Tabela 6). De modo geral, os valores obtidos na cinética de degradação ruminal mantiveram-se na faixa normal descrita na literatura (Berchielli et al., 2000a; Franco et al., 2002; Reis et al., 2003).

A maior DE da MS obtida na dieta FN em relação à FNUR sugere que nesta dieta houve melhor sincronismo entre energia e a liberação de N, pois a energia foi disponibilizada em pequenas quantidades para os microrganismos e a presença de uma fonte de $\mathrm{N}$ extra no rúmen promovida pela contribuição endógena podem ter aumentado a eficiência de aproveitamento de N no rúmen. Quando a uréia é ministrada a um animal com quantidade inadequada de energia disponível no rúmen, o pico de amônia é alto (Tabela 2), o que aumenta as perdas de $\mathrm{N}$, podendo diminuir a eficiência de síntese de proteína microbiana (Tabela 5) e acarretar menores degradabilidades da fibra.

Apesar da idade avançada da forragem utilizada para a produção do feno, os valores de DE encontrados nas dietas experimentais foram bastante similares aos relatados na literatura, o que pode, parcialmente, ser explicado pelo fato de o feno de tifton 85 ter apresentado menores teores lignina, em relação ao conteúdo de parede celular (5,5\% do total da FDN, Tabela 1), quando comparado a outras gramíneas tropicais. Considerando que a lignina é um composto fenólico existente na parede celular considerado indigestível, essa menor concentração pode ser uma das possíveis causas para os altos valores de degradabilidade obtidos nas dietas avaliadas.

A dieta contendo farelo de soja apresentou valores de degradabilidade potencial e efetiva da MS superiores aos encontrados por Souza et al. (2002), de 45,10 e 29,3\% de degradabilidades potencial e efetiva, respectivamente. A dieta cuja fonte de $\mathrm{N}$ foi o farelo de glúten de milho-60 apresentou degradabilidades potencial e efetiva da MS similares às obtidas por esses autores, de 46,6 e 40,6\%, respectivamente, para as degradabilidades potencial e efetiva.

Os valores de degradabilidades potencial e efetiva da FDN da dieta FNFS foram superiores aos encontrados por Souza et al. (2002), de 47,6 e 27,3\% para a dieta com farelo de soja e superior para DP $(53,7 \%)$ para a dieta com farelo de glúten de milho-60. Outros autores não notaram diferenças na degradação da fibra com animais suplementados. Krysl et al. (1989) forneceram suplementação com $0,5 \mathrm{~kg}$ de farelo de soja ou $0,5 \mathrm{~kg}$ de grãos de sorgo floculados a bovinos e não verificaram influência do carboidrato e da proteína no desaparecimento e na taxa de degradação da fibra.

Franco et al. (2002), em estudo com animais com peso vivo médio inicial de $463 \mathrm{~kg}$ em pastagem de capim brachiaria brizantha na época da seca, em condições de alta disponibilidade de forragem (aproximadamente $4.500 \mathrm{~kg} \mathrm{MS} / \mathrm{ha}$ ), também forneceram suplemento alimentar e constataram que a degradabilidade in situ da MS, PB e FDN da forragem não foi afetada pelo nível ou pela degradabilidade da proteína, semelhantemente ao observado no tratamento controle. Galyean \& Owens (1991) e Souza et al. (2002), no 
entanto, verificaram efeito da suplementação protéica ou da ração na degradação da fibra.

\section{Conclusões}

A deficiência de PB e/ou PDR e as diferentes fontes de $\mathrm{N}$ na dieta não afetaram o $\mathrm{pH}$ ruminal, a síntese de proteína microbiana, os parâmetros de degradação e a degradação in situ da MS e FDN do capim-tifton 85.

A dieta com maior degradabilidade de $\mathrm{N}$ (FNUR) apresentou maior nível de $\mathrm{N}-\mathrm{NH}_{3}$.

\section{Literatura Citada}

AGRICULTURAL AND FOOD RESEARCH COUNCIL - AFRC. Energy and protein requirement of ruminants. Wallingford: CAB International, 1993. 159p.

AGRICULTURAL RESEARCH COUNCIL - ARC. Report of the protein group of the agricultural research council working party, on the nutrient requirement of ruminants. London: Commonwealth Agricultural Bureaux, 1984. 45p.

BERCHIELLI, T.T.; FURLAN, C.L.; SALMAN, A.K.D. et al. Degradabilidade ruminal in situ do capim coast-cross (Cynodon dactylon (L.) Pers) comparando-se dois métodos de colheita. ARS Veterinária, v.16, n.3, p.227-231, 2000a

BERCHIELLI, T.T.; ANDRADE, P.; FURLAN, C.L. Avaliação de indicadores internos em ensaios de digestibilidade. Revista Brasileira de Zootecnia, v.29, n.3, p.830-833, 2000b.

BERCHIELLI, T.T.; RODRIGUEZ, N.M.; OSÓRIO NETO, E. et al. Comparação de indicadores de fase sólida para medir fluxo de matéria seca e matéria orgânica no duodeno. Arquivo Brasileiro de Medicina Veterinária e Zootecnia, v.50, n.2, p.147-152, 1998.

BERCHIELLI, T.T.; RODRIGUEZ, N.M.; GONÇALVES, L.C. Polietilenoglicol e cobalto-EDTA como marcadores da fase líquida ruminal. Arquivo Brasileiro de Medicina Veterinária e Zootecnia, v.48, n.4, p.463-471, 1996.

BERCHIELLI, T.T.; RODRIGUEZ, N.M.; ANDRADE, P. et al. Eficiência de síntese de proteína microbiana estimada por diferentes marcadores microbianos. Revista Brasileira de Zootecnia, v.24, n.5, p.800-809, 1995

BRANCO, A.F.; ALCALDE, C.R.; MAIA, F.J. et al. Efeito da fonte de proteína da dieta sobre a digestão de amido em bovinos. Acta Scientiarum, v.23, n.4, p.953-959, 2001.

BÜRGER, P.J.; PEREIRA, J.C.; COELHO DA SILVA, J.F. et al. Taxas de passagem e cinética da degradação ruminal em bezerros holandeses alimentados com dietas contendo diferentes níveis de concentrado. Revista Brasileira de Zootecnia, v.29, n.1, p. 225-235, 2000 .

CAVALCANTE, M.A.D.; PEREIRA, O.G.; VALADARES FILHO, S.C. et al. Níveis de proteína bruta em dietas para bovinos de corte: parâmetros ruminais, balanço de compostos nitrogenados e produção de proteína microbiana. Revista Brasileira de Zootecnia, v.35, n.1, p.203-210, 2006

CECAVA, M.J.; MERCHEN, N.R.; GAY, L.C. et al. Composition of ruminal bacteria harvested from steers as influenced by dietary energy level, feeding frequency and isolation techniques. Journal of Dairy Science, v.73, n.9, p.2480-2488, 1990.

CHRISTENSEN, R.A.; CAMERON, M.R.; KLUSMEYER, T.H. et al. Influence of amount and degradability of dietary protein on production of milk components by lactating Holstein cows. Journal of Dairy Science, v.76, n.11, p.3497-3513, 1993.

CLARK, J.H.; KLUSMEYER, T.H.; CAMERON, M.R. Microbial protein synthesis and flows of nitrogen fractions to the duodenum of dairy cows. Journal of Dairy Science, v.75, n. 8, p.2304-2323, 1992 .

DETMANN, E.; PAULINO, M.F.; VALADARES FILHO, S.C. et al. Níveis de proteína em suplementos para terminação de bovinos em pastejo durante o período de transição seca/águas: digestibilidade aparente e parâmetros do metabolismo ruminal e dos compostos nitrogenados. Revista Brasileira de Zootecnia, v.34, n.4, p.1380-1391, 2005.

FRANCO, G.L.F.; ANDRADE, P.; BRUNO FILHO, J.R. et al. Parâmetros ruminais e desaparecimento da FDN da forragem em bovinos suplementados em pastagem na estação das águas. Revista Brasileira de Zootecnia, v.31, n.6, p.2340-2349, 2002.

FREGADOLLI, F.L.; ZEOULA, L.M.; BRANCO, A.F. et al. O. Efeito das fontes de amido e nitrogênio de diferentes degradabilidades ruminais. 2. pH, concentração de amônia no liquido ruminal e eficiência de síntese microbiana. Revista Brasileira de Zootecnia, v.30, n.3, p.870-879, 2001

GALYEAN, M.L.; OWENS, F.N. Effects of diet composition and level of feed intake on site and extent of digestion in ruminants. In: TSUDA, T.; SASAKI, Y.; KAWASHIMA, R. (Eds.) Physiological aspects of digestion and metabolism in ruminants. New York: Academic Press, 1991. p.483-514.

KRYSL, L.J.; BRANINE, M.E.; CHEEMA, A.U. et al. Influence of soybean and sorghum grain supplementation on intake, digesta kinetics, ruminal fermentation, site and extent of digestion and microbial protein synthesis in beef steers grazing blue gram rangeland. Journal of Animal Science, v.67, n.11, p.30403051, 1989

MENDES, A.R.; EZEQUIEL, J.M.B.; GALATI, R.L. et al. Cinética digestiva e eficiência de síntese de proteína microbiana em novilhos alimentados com farelo de girassol e diferentes fontes energéticas. Revista Brasileira de Zootecnia, v.35, n.1, p.264-274, 2006.

MERTENS, D.R.; LOFTEN, J.R. The effect of starch on forage fiber digestion kinetics in vitro. Journal of Dairy Science, v.63, n.9, p.1437-1446, 1980 .

NATIONAL RESEARCH COUNCIL - NRC. Nutrient requirements of dairy cattle. 7. rev. ed. Washington, D.C.: National Academy of Sciences, 2001. 381p.

ØRSKOV, E.R.; McDONALD, I. The estimation of protein degradability in the rumen from incubation measurements of feed in weighted according rate passage. Journal of Agricultural Science, v.92, n.2, p.499-503, 1979.

OWENS, F.N.; GOETSCH, A.L. Ruminal fermentation. In: CHURCH, D.C. (Ed.) The ruminant animal digestive physiology and nutrition. Englewood Cliff: O \& Books Inc., 1988, p. 146-171.

OWENS, F.N.; ZINN, R. Metabolismo de la proteína en los rumiantes. In: CHURCH, D.C. (Ed.) El rumiante: fisiología digestiva e nutrición. 3.ed. Zaragoza: Acribia, 1988. p.255-281.

REIS, R.A.; BERCHIELLI, T.T.; ANDRADE, P. et al. Valor nutritivo do feno de coast-cross (Cynodon dactylon L. Pers) submetido à amonização. ARS Veterinária, v.19, n.2, p.143-149, 2003.

ROFFLER, R.E.; SATTER, L.D. Relationship between ruminal ammonia and nonprotein nitrogen utilization by ruminants. I. Development of a model for predicting nonprotein nitrogen utilization by cattle. Journal of Dairy Science, v. 58 , n.12, p.1880-1898, 1974

ROSTAGNO, H.S.; SILVA, D.J.; COSTA, P.M.A. et al. Composição de alimentos e exigências nutricionais de aves e suínos. Viçosa, MG: Universidade Federal de Viçosa, 1992. 60p.

RUSSELL, J.B.; O'CONNOR, J.D.; FOX, D.G. et al. A net of carbohydrate and protein system for evaluating cattle diets. I. Ruminal fermentation. Journal of Animal Science, v.70, n.11, p.3551-3561, 1992.

SALISBURY, M.W.; KREHBIEL, C.R.; ROSS, T.T. et al. Effects of supplemental protein type on intake, nitrogen balance, and site, and extent of digestion in whiteface wethers consuming 
low-quality grass hay. Journal of Animal Science, v.82, n.12, p.3567-3576, 2004.

STATISTICAL ANALYSES SYSTEM - SAS. SAS system: SAS/ STAT. version 8.0. Cary: 1999. (CD-ROM).

SATTER, L.D.; SLYTER, L.L. Effect of ammonia concentration on rumen microbial protein production in vitro. British Journal Nutrition, v.32, n.2, p.199-208, 1974.

SILVA, D.J.; QUEIROZ, A.C. Análise de alimentos (métodos químicos e biológicos). 3.ed. Viçosa, MG: Editora UFV, 2002 $235 \mathrm{p}$.

SNIFFEN, C.J.; O'CONNOR, J.D.; Van SOEST, P.J. et al. A net carbohydrate and protein system for evaluation cattle diets. II. Carbohydrate and protein availability. Journal of Animal Science, v.70, n.11, p.3562-3577, 1992.

SOUZA, M.A.; EZEQUIEL, J.M.B.; ROSSI JR., P. et al. Efeitos de fontes nitrogenadas com distintas degradabilidades sobre o aproveitamento da fibra, do nitrogênio e do amido em rações para bovinos. Revista Brasileira de Zootecnia, v.31, n.5, p.2139-2148, 2002.

ÚDEN, P.; COLLUCCI, P.E.; Van SOEST, P.J. Investigation of chromium, cerium and cobalt as marker in digesta. Rate of passage studies. Journal Science and Food Agriculture, v. 31, n.7, p.625-632, 1980.

USHIDA, K.; LASSALAS, B.; JOUANY, J.P. Determination of assay parameters for RNA analysis in bacterial and duodenal samples by spectrophotometry. Influence of sample treatment and preservation. Reproduction Nutrition Development, v.25, n.6, p.1037-1046, 1985.

VALADARES FILHO, S.C.; COELHO DA SILVA, J.F.; SANT'ANNA, R. et al. Composição de bactérias ruminais e absorção de aminoácidos microbianos no intestino delgado de novilhos holandeses, nelores e búfalos mestiços. Revista da Sociedade Brasileira de Zootecnia, v.19, n.5, p.431-440, 1990a.

VALADARES FILHO, S.C.; COELHO DA SILVA, J.F.; LEÃO, M.I. et al. Digestibilidade in vitro e alguns parâmetros de fermentação ruminal medidos em novilhos holandeses, nelores e búfalos mestiços alimentados com ração purificada. Revista da Sociedade Brasileira de Zootecnia, v.19, n.5, p.441-449, 1990b.

ZINN, R.A.; OWENS, F.N. A rapid procedure for purine measurement and its use for estimating net ruminal protein synthesis. Canadian Journal of Animal Science, v.66, n.1, p.157-166, 1986.

SILVA, E.A.; BERCHIELLI, T.T.; REIS, R.A. Teores de proteína bruta para bovinos alimentados com feno de capim-Tifton 85 : consumo e digestibilidades total e parcial. Revista Brasileira de Zootecnia, v.36, n.1, p.237-245, 2007.

Recebido: 01/10/05 Aprovado: 16/08/06 